\title{
Food insecurity and subsequent weight gain in women
}

\author{
Sonya J Jones ${ }^{1, *}$ and Edward A Frongillo ${ }^{2}$ \\ ${ }^{1}$ Center for Research in Nutrition and Health Disparities, University of South Carolina Arnold School of Public Health, \\ 2718 Middleburg Drive, 2nd Floor, Columbia, SC 29204, USA: ${ }^{2}$ Department of Health Education Promotion and \\ Behavior, University of South Carolina, Columbia, SC, USA
}

Submitted 21 October 2005: Accepted 3 April 2006

\begin{abstract}
Objective: Cross-sectional data indicate that a relationship between household food insecurity and overweight exists among women in the USA. Cross-sectional data cannot determine if food insecurity leads to overweight as some have hypothesised. The purpose of the present study was to examine the relationship of food insecurity with subsequent weight gain in women using data from the Panel Study of Income Dynamics (PSID).

Design, setting and subjects: Panel data from the 1999 and 2001 PSID, a nationally representative sample of households, were analysed using multivariate regression procedures.

Results: Average weight gain among all women $(n=5595)$ was $1.1 \mathrm{~kg}$ on average over the two years. There were no significant differences in the percentages of women who gained a clinically significant amount $(2.3 \mathrm{~kg})$ by food insecurity status. Overweight women who were on a weight-gain trajectory during the 2-year period gained less if they were food-insecure. This relationship was not observed among healthy-weight or obese women.

Conclusions: Overall, food insecurity does not appear to be strongly associated with subsequent weight gain in women.
\end{abstract}

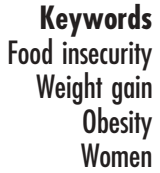

Cross-sectional studies have found that food insecurity is associated with increased risk of a woman being classified as overweight ${ }^{1-4}$. National survey data indicate that women in households that are moderately food-insecure are more likely to be overweight than are women in foodsecure households ${ }^{1,2}$. In a smaller sample in upstate New York, women in households that were moderately food-insecure had higher body mass index (BMI) than women in food-secure or severely food-insecure households ${ }^{5}$. While these reported associations between food insecurity do not provide evidence for causal inference, some have hypothesised that food insecurity causes obesity $^{2,6}$. Cross-sectional data are limited, however, and cannot reveal the timing and direction of the relationship between food insecurity and weight status or weight gain ${ }^{7}$.

Data from the Panel Study of Income Dynamics (PSID) allowed us to begin to understand if the experience of food insecurity leads to obesity in women by examining how food insecurity is related to subsequent weight gain. This nationally representative, longitudinal study of USA households collected food insecurity data for households and self-reported heights and weights for heads of households and wives in 1999 and 2001. Elsewhere, we have reported that changing food insecurity status has no significant effect on absolute weight change in women, and that women who are persistently food-insecure experience less weight change than those who are not persistently food-insecure ${ }^{8}$. In the present study, two questions are addressed. First, does experiencing food insecurity lead to subsequent weight gain in women in the USA? Second, do other risk factors for weight gain help explain any relationship between food insecurity and weight gain?

\section{Methods}

\section{Data}

The PSID began in 1968 to study economic dynamics of USA households?. The PSID included 6241 families that participated in the study in both 1999 and 2001. In accordance with the coding schemes used in the original sample from 1968, any household with both a male and a female was coded with males as heads and females as wives. In households with only one adult, heads of household may be either male or female. All heads and wives were recoded to be males and females regardless of their head of household status. To account for complex sampling strategies, the entry of new families into the original sample and attrition, the PSID includes post-stratification weights that calibrate the estimates to the demographic characteristics of the US population?. Weights were used in all analyses. 


\section{Outcomes}

\section{BMI and weight gain}

Heights and weights were reported by study respondents in pounds and inches. Weight gain was calculated as the absolute difference in kilograms between 2001 and 1999 self-reported weights. BMI $\left(\mathrm{kg} \mathrm{m}^{-2}\right)$ was calculated. A categorical variable for initial weight status was created to classify women as 'healthy-weight' if BMI was less than $25 \mathrm{~kg} \mathrm{~m}^{-2}$, 'overweight' if BMI was greater than or equal to $25 \mathrm{~kg} \mathrm{~m}^{-2}$ and less than $30 \mathrm{~kg} \mathrm{~m}^{-2}$, or 'obese' if BMI was greater than or equal to $30 \mathrm{~kg} \mathrm{~m}^{-2}$ based on their 1999 height and weight. A dichotomous variable was created to categorise all women as 'weight gainers' (gained greater than $2.3 \mathrm{~kg}$ or approximately $5 \mathrm{lb}$ in 2 years) or not. Studies of clinically significant weight gain have defined a major weight gain variably, from $1 \mathrm{~kg}$ per year ${ }^{10}, 1.7 \mathrm{~kg}$ per year $^{11}, 2.7 \mathrm{~kg}$ per year ${ }^{12}$ to $3.5 \mathrm{~kg}$ per year $(5 \%$ of the average PSID woman's body weight ${ }^{13}$. Because of the widely varying definitions available in the literature, weight gain of $2.3 \mathrm{~kg}$ (i.e. $5 \mathrm{lb}$ ) over 2 years was selected based on the classification system recommended by St Jeor et al. ${ }^{14}$. For the purposes of regression analysis, all women who reported a weight gain of greater than $50 \mathrm{lb}(27.2 \mathrm{~kg})$ were recoded as gaining $50 \mathrm{lb}$ to reduce the potentially excessive influence of these values. Sensitivity analyses showed that this recoding did not alter the results.

\section{Exposure}

\section{Housebold food security}

Food security was measured using the 18-item scale of the US Department of Agriculture's (USDA) Household Food Security Survey Module (HFSSM) with a reference period of the 12 months prior to administration of the questionnaire $^{15}$. This scale has been shown to be valid and reliable in the general population ${ }^{16}$. The standard USDA food security variable with four categories, 'food secure', 'food insecure without hunger', 'food insecure with moderate hunger' and 'food insecure with severe hunger', was available in the 1999 dataset. From this variable we constructed a two-category variable that combined the food-insecure without hunger, moderate and severe hunger households into a single category, owing to small numbers $(n=89)$ of households in the third and fourth categories of the original variable that included a woman with height and weight data. Food security status in 1999 is referred to as baseline food security status for the purposes of this analysis. There is a growing interest in the food security literature in the 'marginally' food-insecure ${ }^{17,18}$. Because the standard USDA food security variable puts marginally food-insecure women in the food-secure category, we also analysed our data using a variable that separated out marginal food insecurity, but found no differences in our results.

\section{Individual covariates}

Age

Continuous age in years was categorised as 18-24, 25-39, 40-64 and 65-74 years. Women below the age of 18 ( $n=7$ total, 3 with weight data) or above the age of 74 ( $n=333$ total, 264 with weight data) were excluded.

\section{Race/ethnicity}

Each individual was classified in the PSID as Caucasian, Black, Native American, Hispanic or Asian/Pacific Islander based on the respondent's report. We re-classified as Caucasian, Black, Hispanic or Other due to the small numbers of members of other ethnic groups included in this study ( $n=27$ American Indians total, 23 with weight data; $n=111$ Asian/Pacific Islanders total, 90 with weight data).

\section{Self-rated bealth}

The PSID asked respondents if they would rate their own health as 'excellent', 'very good', 'good', 'fair' or 'poor'. Due to small cell sizes, the fair and poor categories were combined to create a four-category variable ranging from 'excellent' to 'fair or poor'.

\section{Physical activity}

Respondents in the PSID were asked: 'How often do you participate in vigorous physical activity, such as heavy housework, aerobics, running, swimming or bicycling?' Based on the American College of Sports Medicine (ACSM) recommendations of participation in vigorous physical activity most days of the week, a categorical variable was created to classify respondents as 'inactive' if they responded that they participated less than once per week, 'active but not meeting recommendations' if they participated 1 to 4 times per week, and 'meeting recommendations' if they participated 5 or more times per week.

\section{Smoking}

PSID respondents were asked if they smoked cigarettes and if so how many per day. A categorical variable was created that classified respondents as non-smokers if they responded 'no' to the question: 'Do you smoke?' If the respondent reported smoking, they were classified as smoking less than one pack or 20 cigarettes per day or more than one pack per day based on their report of total cigarettes per day.

\section{Alcohol consumption}

Respondents reported if they drank any alcoholic beverages and if so how much, in response to the following questions: 'Do you ever drink any alcoholic beverages, such as beer, wine or liquor?' and 'On average, do you have less than one drink a day, one to two drinks in a day, three to four drinks in a day, or five or more drinks 
in a day?' Due to the small numbers of women who reported drinking more than three drinks per day $(n=249$ total, 214 with weight data), women were classified as consuming one or more drinks per day or less than one drink per day for the purposes of these analyses.

\section{Housebold covariates}

Presence of a young child

To account for the possibility of a recent pregnancy, we created a dichotomous variable that indicated whether or not there was a child under the age of 2 years in the household between the years 1999 and 2001. There was no variable available in the data to assess actual pregnancy status.

\section{Income}

Previous-year family income reported in 1999 and 2001 was compared to the census poverty standards to calculate an income-to-poverty ratio (IPR). A categorical variable was also created to classify households as less than 100\%, 100-130\%, 130-185\%, 185-250\%, 250-350\% and above $350 \%$ of the IPR.

\section{Marital status}

Female respondents were classified as 'never married', 'married', 'unmarried but cohabiting', 'widowed', 'divorced' or 'separated', based on respondent's report.

\section{Housing status}

From responses to PSID question 'Do you (or anyone else in your family living there) own the (home/apartment), pay rent, or what?', a two-category variable was created to categorise households as owning their home or not.

\section{Statistical analyses}

Analyses were based on a final sample of 5303, after excluding biologically implausible weights and age younger than 18 years or older than 74 years. Analyses were conducted in STATA Version 8.0 (Stata Corp.). Univariate statistics were calculated using the family-level sample weights provided with PSID data using SVY commands to account for design effects related to complex probability sampling. Bivariate and multivariate statistics that included only one year of data (1999 or 2001) used the weights for the matching year. All analyses conducted that included data from both years were weighted by the 2001 sample weights.

Crude and stratified probabilities of being classified as a weight gainer (gaining more than $2.3 \mathrm{~kg}$ in 2 years) were calculated. Logistic regression was used to estimate the probability of being a weight gainer by baseline food security status. Results are reported as predicted probabilities of being classified as a weight gainer.

Crude and adjusted mean weight changes were calculated by baseline food security and baseline weight status for women who gained $2.3 \mathrm{~kg}$ or greater. T-statistics were calculated to test for mean differences in amount of weight gained. Multiple linear regression analysis was conducted to control for covariates. Results are reported as means and unstandardised coefficients.

The analytic strategy of examining both whether or not women gained a clinically significant amount of weight and the amount of weight change among those who did gain weight was adopted to understand whether food insecurity leads to subsequent additional weight gain and also the amount of that change for those on a weight-gain trajectory. Other studies of weight gain have employed a variety of similar strategies, such as examining the amount of weight gain in those attempting a weight $\operatorname{loss}^{11}$, the amount of weight gain following a greater-thanrecommended pregnancy gain ${ }^{19}$ and stratifying analysis of any weight loss and any weight gain ${ }^{20}$.

\section{Results}

\section{Description of the sample}

Women in the analytic sample reported a mean weight gain of $1.06 \mathrm{~kg}$ from 1999 to 2001 (Table 1). Healthyweight women reported higher weight gains than average, and overweight and obese women reported lower weight gains. Food-insecure women reported gaining $0.8 \mathrm{~kg}$ on average.

Overall, food-insecure women were younger, more likely to report being of Black or Hispanic origin, more likely to rate their health as fair or poor, less likely to report engaging in any vigorous physical activity, slightly more likely to smoke, and more likely to report abstaining from alcohol than food-secure women (Table 1). Food-insecure women lived in households with lower IPR and were never married, cohabiting, divorced or separated more than were food-secure women. About 18.5\% of foodinsecure women reported having a child in the two years following the report of food insecurity.

Overweight and obese women were slightly older, more likely to report being of Black or Hispanic origin, more likely to rate their health as fair or poor, less likely to report meeting activity recommendations, slightly more likely to smoke and to abstain from alcohol, and were more likely to have a lower IPR than healthy-weight women. Fewer overweight and obese women reported being married or cohabiting than healthy-weight women and were slightly less likely to report having a child between 1999 and 2001. Fewer obese women reported owning their own homes.

\section{Weight gain}

Food insecurity was not related to women subsequently gaining a clinically significant amount of weight, regardless of initial weight status (Fig. 1). Among women in foodinsecure households, the probability of reporting a weight gain of $2.3 \mathrm{~kg}$ or more was highest among women who were not overweight or obese (32\%), followed by obese 
Table 1 Characteristics of women in the 1999 Panel Study of Income Dynamics

\begin{tabular}{|c|c|c|c|c|c|c|}
\hline & \multirow[b]{2}{*}{ All women } & \multicolumn{3}{|c|}{ Women with $1999 \mathrm{BMI}$} & \multicolumn{2}{|c|}{ Food security } \\
\hline & & $<25 \mathrm{~kg} \mathrm{~m}^{-2}$ & $25-29 \mathrm{~kg} \mathrm{~m}^{-2}$ & $\geq 30 \mathrm{~kg} \mathrm{~m}^{-2}$ & Secure & Insecure \\
\hline$n$ & 5595 & 2913 & 1541 & 1141 & 5406 & 447 \\
\hline Weight change $(\mathrm{kg})$, mean $\pm \mathrm{SE}$ & $1.1 \pm 0.1$ & $1.7 \pm 0.1$ & $0.4 \pm 0.3$ & $-0.1 \pm 0.5$ & $1.1 \pm 0.1$ & $0.8 \pm 0.5$ \\
\hline Age (years), mean & 47.0 & 45.2 & 46.7 & 48.5 & 47.5 & 35.5 \\
\hline \multicolumn{7}{|l|}{ Race/ethnicity (\%) } \\
\hline White, non-Hispanic & 78.9 & 84.2 & 75.0 & 67.0 & 81.4 & 44.9 \\
\hline African American & 11.7 & 6.9 & 13.4 & 25.1 & 10.4 & 23.6 \\
\hline Hispanic & 5.6 & 4.4 & 7.9 & 6.2 & 4.6 & 26.1 \\
\hline Other & 3.8 & 4.6 & 3.7 & 1.7 & 3.6 & 5.5 \\
\hline \multicolumn{7}{|l|}{ Self-rated health (\%) } \\
\hline Excellent & 21.5 & 28.0 & 16.7 & 8.9 & 22.9 & 13.5 \\
\hline Very good & 33.4 & 36.0 & 34.1 & 25.1 & 34.8 & 20.1 \\
\hline Good & 30.5 & 25.5 & 33.5 & 38.9 & 29.5 & 42.0 \\
\hline Fair or poor & 14.6 & 10.5 & 15.7 & 27.1 & 12.8 & 24.4 \\
\hline \multicolumn{7}{|l|}{ Participate in vigorous activity (\%) } \\
\hline Less than once per week & 38.7 & 44.5 & 55.7 & 67.1 & 37.4 & 50.2 \\
\hline $1-4$ times per week & 43.4 & 41.2 & 32.0 & 22.3 & 44.6 & 29.9 \\
\hline 5 or more times per week & 17.9 & 14.3 & 12.4 & 10.6 & 18.3 & 19.8 \\
\hline \multicolumn{7}{|l|}{ Current smoking (\%) } \\
\hline No smoking & 82.5 & 80.1 & 84.5 & 85.4 & 83.7 & 72.1 \\
\hline $1-19$ cigarettes per day & 10.2 & 12.2 & 7.6 & 9.0 & 9.5 & 17.9 \\
\hline 20 or more cigarettes per day & 7.3 & 7.7 & 7.9 & 5.6 & 6.8 & 9.1 \\
\hline \multicolumn{7}{|l|}{ Current alcohol consumption (\%) } \\
\hline Never & 47.1 & 40.5 & 51.4 & 59.4 & 45.7 & 62.0 \\
\hline Less than 1 drink per day & 45.6 & 50.8 & 41.8 & 36.9 & 46.7 & 34.5 \\
\hline More than 1 drink per day & 7.4 & 8.8 & 6.8 & 3.7 & 7.6 & 3.2 \\
\hline \multicolumn{7}{|l|}{ Household factors } \\
\hline Food-insecure (\%) & 5.1 & 3.9 & 5.7 & 7.6 & 0.0 & 100.0 \\
\hline \multicolumn{7}{|l|}{ Income-to-poverty ratio (\%) } \\
\hline Below $100 \%$ & 8.3 & 6.2 & 7.3 & 16.3 & 4.8 & 30.2 \\
\hline $100-129 \%$ & 4.3 & 2.9 & 5.1 & 7.5 & 2.8 & 17.5 \\
\hline $130-184 \%$ & 8.1 & 6.5 & 10.1 & 9.2 & 6.6 & 15.4 \\
\hline $185-249 \%$ & 9.8 & 8.8 & 10.6 & 12.1 & 8.7 & 15.0 \\
\hline $250-350 \%$ & 16.4 & 15.6 & 16.9 & 18.6 & 16.5 & 11.7 \\
\hline Above $350 \%$ & 53.2 & 60.0 & 49.2 & 36.4 & 60.9 & 10.1 \\
\hline \multicolumn{7}{|l|}{ Marital status (\%) } \\
\hline Never married & 11.4 & 11.2 & 9.8 & 15.3 & 10.1 & 22.2 \\
\hline Married & 61.6 & 65.9 & 59.6 & 49.2 & 64.6 & 44.6 \\
\hline Cohabitation & 3.6 & 3.5 & 3.3 & 2.8 & 3.2 & 7.3 \\
\hline Widowed & 9.5 & 7.0 & 12.2 & 14.7 & 9.4 & 2.3 \\
\hline Divorced & 11.4 & 10.4 & 11.7 & 14.9 & 10.4 & 15.9 \\
\hline Separated & 2.6 & 2.1 & 3.5 & 3.1 & 2.2 & 7.8 \\
\hline Had a child between 1999 \& 2001 (\%) & 4.2 & 5.2 & 4.3 & 4.6 & 4.4 & 18.5 \\
\hline \multicolumn{7}{|l|}{ Housing status (\%) } \\
\hline Owns home & 71.9 & 74.1 & 73.2 & 65.9 & 23.6 & 41.0 \\
\hline Rents & 28.1 & 25.9 & 26.8 & 34.1 & 76.4 & 59.0 \\
\hline
\end{tabular}

$\mathrm{BMI}$ - body mass index; SE - standard error.

women (29\%) and overweight women (25\%). Among women in food-secure households, the probability of

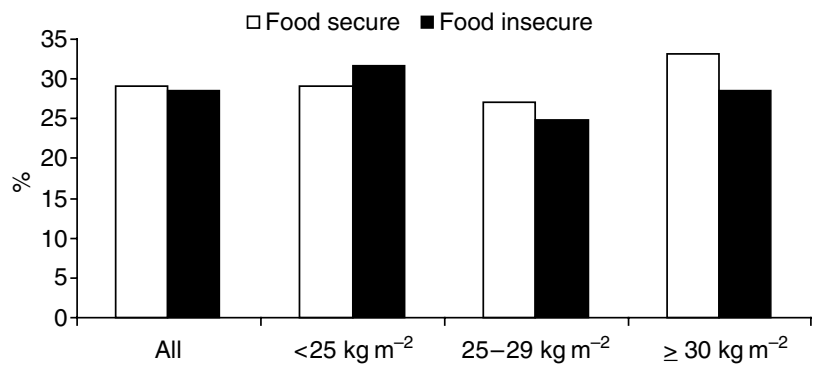

Fig. 1 Women (\%) reporting a gain of $2.3 \mathrm{~kg}$ or more in 2 years by initial food security and weight status reporting a weight gain was highest among women who were obese at baseline (33\%), followed by women who were not overweight or obese (29\%) and overweight women (27\%).

Among women who gained at least $2.3 \mathrm{~kg}$, baseline food insecurity was associated with a greater subsequent weight gain among some groups (Table 2). Women weight gainers who were overweight at baseline gained $2.2 \mathrm{~kg}$ more if they were food-secure than if they were foodinsecure $(P<0.004)$. Women weight gainers who were healthy-weight or obese gained more if they were foodinsecure than if they were food-secure, but the differences were not significant $(1.7 \mathrm{~kg}, P<0.088$ and $2.5 \mathrm{~kg}$, $P<0.281$, respectively). Similar to the results in Fig. 1, 
Table 2 Mean reported weight gain $(\mathrm{kg})$ among women who gained more than $2.3 \mathrm{~kg}$ in 2 years

\begin{tabular}{|c|c|c|c|c|}
\hline & $\begin{array}{c}\text { All } \\
\text { women } \\
\text { gainers }\end{array}$ & $\begin{array}{c}\text { Not } \\
\text { overweight }\end{array}$ & Overweight & Obese \\
\hline Food secure & 8.3 & 7.3 & 8.8 & 10.4 \\
\hline Food insecure & 9.4 & 9.0 & 6.6 & 12.9 \\
\hline Difference & 1.1 & 1.7 & -2.2 & 2.5 \\
\hline $\begin{array}{l}P \text {-value for test: food } \\
\text { secure }=\text { food insecure }\end{array}$ & 0.161 & 0.088 & 0.004 & 0.281 \\
\hline $\begin{array}{l}P \text {-value for test: difference } \\
\text { (not overweight) }=\text { difference } \\
\text { (overweight or obese) }\end{array}$ & - & - & 0.002 & 0.750 \\
\hline
\end{tabular}

the data in Table 2 demonstrate that the relationship between weight gain and food insecurity is different in overweight women than in healthy-weight and obese women. That is, being food-insecure and overweight leads to less additional weight than being food-insecure and not overweight (difference $=3.9 \mathrm{~kg}, P<0.002$ ).

Table 3 presents the results of two regression analyses: a logistic regression for whether women had a clinically significant weight gain and an ordinary least-squares regression of the amount of weight gain among weight gainers. After adjusting for covariates using logistic regression, food insecurity status in 1999 was not a significant predictor of a clinically significant subsequent weight gain (i.e. $2.3 \mathrm{~kg}$ or more), consistent with the unadjusted findings presented in Fig. 1. Covariates that significantly predicted a weight gain of $2.3 \mathrm{~kg}$ or more included smoking one pack or more versus not smoking ( $\beta=0.29$ and 0.38 , respectively, $P<0.05$ ). Covariates that were significantly associated with decreased probability of being a weight gainer included meeting ACSM recommendations for physical activity and being 65-74 years of age compared with 18-25 years. Neither baseline weight status nor income status predicted the probability of being a weight gainer.

Table 3 also presents the results of multiple linear regression analysis predicting the amount of weight gain among women who reported gaining $2.3 \mathrm{~kg}$ or more. Food insecurity was not a significant predictor of amount of weight gain in multivariate adjusted analysis. However, the interaction between food insecurity status and overweight status was significant. Among weight-gaining women who were overweight at baseline, those who were foodinsecure gained $2.4 \mathrm{~kg}$ less than those who were foodsecure.

\section{Discussion}

Evidence from cross-sectional studies had suggested that mild to moderate food insecurity was associated with an approximately $30 \%$ increased risk of overweight in women $^{1,2,4}$. Using the nationally representative sample of women from the PSID, this study also observed an association between overweight status and food insecurity in women in a cross-sectional analysis of 1999 data. While these cross-sectional analyses cannot indicate the direction of the association, some authors have hypothesised that food insecurity leads to overweight in women. To test this hypothesis, data have been needed to examine if food insecurity at one point in time leads to increased weight gain that will presumably, in turn, lead to overweight. Our findings in this paper suggest that, in US women, food insecurity prior to baseline does not increase a woman's probability of gaining a clinically significant amount of weight over a 2 -year period. Among women who gained a clinically significant amount of weight, food-insecure women gained between 6.5 and $12.9 \mathrm{~kg}$ depending on initial weight status, but overweight, food-insecure women gained significantly less weight than overweight, foodsecure women. Overall, these results suggest that food insecurity at one time point is not strongly or consistently associated with women's subsequent weight gain. After controlling for covariates that might have confounded the relationship between food insecurity and subsequent weight gain, our initial findings were only slightly altered.

Many of the covariates that were predictive of weight gain are consistent with other studies of weight gain. Among the health behaviours examined in these analyses, physical activity and smoking were predictive of weight gain and were associated with food insecurity. Household poverty was associated with weight gain and strongly associated with food insecurity in unadjusted analysis. Other studies have also suggested that some aspects of socio-economic status are likely to be associated with weight gain $^{12,21}$. We found a modest association between having a child during the observational period and weight gain. Other longitudinal studies indicated that women retain between 0.5 and $3 \mathrm{~kg}$ in the 2.5 years following pregnancy and that women who gain more than the recommended amount for their pre-pregnancy weight status during pregnancy are significantly more likely to gain additional weight in the postpartum period ${ }^{19,22}$.

Although the height and weight data in the PSID are self-reported and subject to reporting and non-response bias $^{23}$, the average amount of weight gain was consistent with measured weight gains from the CARDIA study suggesting that women are gaining 0.7 to $1.2 \mathrm{~kg}$ per year on average. Furthermore, reporting bias for weight change is less likely than that for weight at one time because of similar bias in both weights that constitute the change. The average amount of weight gained varied by initial weight status. Further studies are needed to confirm these results, ideally that use measured weights.

This study has found that food insecurity at one point in time is not strongly associated with subsequent weight gain over a 2-year period in US women. Given that a number of other sociodemographic and behavioural factors are associated both with food insecurity and with weight gain, future studies should aim to understand 
Table 3 The effect of baseline food insecurity on subsequent weight gain in women controlling for potential confounding factors

\begin{tabular}{|c|c|c|c|c|}
\hline & $\begin{array}{l}\text { Unstandardised logistic } \\
\text { regression coefficient } \\
\text { (outcome is clinically } \\
\text { significant weight gain) }\end{array}$ & $P$-value & $\begin{array}{c}\text { Unstandardised OLS coefficient } \\
\text { (outcome is amount } \\
\text { of gain among gainers) }\end{array}$ & $P$-value \\
\hline Constant & -0.76 & 0.009 & 8.2 & 0.000 \\
\hline $\begin{array}{l}\text { Food-insecure in } 1999 \text { vs. food-secure } \\
\text { Weight status in } 1999\end{array}$ & -0.28 & 0.385 & 0.68 & 0.637 \\
\hline Overweight vs. healthy weight & -0.05 & 0.657 & 1.35 & 0.048 \\
\hline Obese vs. healthy weight & 0.16 & 0.247 & 2.53 & 0.004 \\
\hline \multicolumn{5}{|l|}{ Food insecurity $\times$ weight status } \\
\hline $\begin{array}{l}\text { Insecure } \times \text { overweight } \\
\text { Insecure } \times \text { obese }\end{array}$ & $\begin{array}{r}0.45 \\
-0.04\end{array}$ & $\begin{array}{l}0.587 \\
0.934\end{array}$ & $\begin{array}{r}-3.03 \\
0.71\end{array}$ & $\begin{array}{l}0.048 \\
0.797\end{array}$ \\
\hline \multicolumn{5}{|l|}{ Health behavioural factors } \\
\hline \multicolumn{5}{|l|}{ Physical activity } \\
\hline $\begin{array}{l}1-4 \text { times per week vs. none } \\
5 \text { or more times per week vs. none }\end{array}$ & $\begin{array}{l}-0.08 \\
-0.31\end{array}$ & $\begin{array}{l}0.465 \\
0.034\end{array}$ & $\begin{array}{l}0.06 \\
1.35\end{array}$ & $\begin{array}{l}0.896 \\
0.097\end{array}$ \\
\hline \multicolumn{5}{|l|}{ Smoking } \\
\hline $\begin{array}{l}\text { Less than } 1 \text { pack per day vs. none } \\
\text { More than } 1 \text { pack per day vs. none }\end{array}$ & $\begin{array}{l}0.29 \\
0.38\end{array}$ & $\begin{array}{l}0.051 \\
0.026\end{array}$ & $\begin{array}{l}0.25 \\
1.40\end{array}$ & $\begin{array}{l}0.738 \\
0.212\end{array}$ \\
\hline \multicolumn{5}{|l|}{ Alcohol consumption } \\
\hline Less than 1 drink per day vs. none & -0.08 & 0.417 & 0.66 & 0.207 \\
\hline More than 1 drink per day vs. none & -0.19 & 0.299 & -1.07 & 0.122 \\
\hline \multicolumn{5}{|l|}{ Self-reported health } \\
\hline Fair vs. poor & 0.06 & 0.641 & 0.46 & 0.401 \\
\hline Very good vs. poor & 0.12 & 0.345 & 0.46 & 0.406 \\
\hline Excellent vs. poor & -0.14 & 0.422 & 2.02 & 0.069 \\
\hline \multicolumn{5}{|l|}{ Sociodemographic factors } \\
\hline \multicolumn{5}{|l|}{ Household income-to-poverty ratio } \\
\hline $100-129 \%$ vs. less than $100 \%$ & -0.05 & 0.853 & 0.81 & 0.584 \\
\hline $130-184 \%$ vs. less than $100 \%$ & 0.16 & 0.513 & -0.18 & 0.857 \\
\hline $185-249 \%$ vs. less than $100 \%$ & 0.17 & 0.472 & 0.96 & 0.508 \\
\hline $250-350 \%$ vs. less than $100 \%$ & 0.32 & 0.151 & 0.99 & 0.351 \\
\hline $350 \%$ and above vs. less than $100 \%$ & 0.10 & 0.659 & 0.620 & 0.516 \\
\hline \multicolumn{5}{|l|}{ Housing status } \\
\hline Owns own home vs. rents or lives with someone else & 0.07 & 0.593 & -1.18 & 0.075 \\
\hline \multicolumn{5}{|l|}{ Marital status } \\
\hline Never married vs. married & -0.03 & 0.874 & -0.32 & 0.711 \\
\hline Widowed vs. married & 0.04 & 0.862 & 0.23 & 0.898 \\
\hline Divorced vs. married & -0.09 & 0.601 & 0.24 & 0.811 \\
\hline Separated vs. married & 0.50 & 0.100 & -0.79 & 0.509 \\
\hline Cohabiting vs. married & 0.41 & 0.061 & 0.98 & 0.513 \\
\hline \multicolumn{5}{|l|}{ Age } \\
\hline $26-40$ years vs. $18-25$ years & -0.29 & 0.253 & -0.41 & 0.675 \\
\hline $41-64$ years vs. $18-25$ years & -0.33 & 0.101 & -0.88 & 0.384 \\
\hline $65-74$ years vs. $18-25$ years & -0.63 & 0.012 & -2.61 & 0.102 \\
\hline Had a child in past two years & 0.23 & 0.195 & -1.11 & 0.129 \\
\hline \multicolumn{5}{|l|}{ Race/ethnicity } \\
\hline African American vs. white & 0.23 & 0.110 & 0.46 & 0.510 \\
\hline Hispanic vs. white & -0.17 & 0.435 & 0.88 & 0.384 \\
\hline Other vs. white & -0.28 & 0.253 & -2.61 & 0.102 \\
\hline
\end{tabular}

OLS - ordinary least squares.

the mechanisms through which poverty and food insecurity may be linked to body weight. The results of the present study suggest that examining the patterns of weight gain among women who are initially overweight and experience food insecurity may be a fruitful area for longitudinal research with multiple measures of food insecurity and weight status. Such longitudinal research might be done from a life-course perspective. Having multiple measurements would allow investigators to examine transitions, turning points, timing in life, adaptive strategies and possibly linking of lives, thus going beyond the examination of trajectories and contextual influences examined in this study ${ }^{24}$.

\section{Acknowledgements}

Sources of funding: This work was supported by cooperative agreement 43-3AEM-3-80 104 with the United States Department of Agriculture Economic Research Service.

Conflict of interest declaration: There are no conflicts of interest.

Authorship responsibilities: S.J.J. drafted the first draft and performed all analysis. E.A.F. edited, wrote additional material, provided leadership on analytical approaches and worked to conceptualise the research framework. 
Acknowledgements: The authors would like to acknowledge the helpful comments of Barbara Laraia on an earlier draft of this paper and the support of Sarah Gause in the submission of the final draft. Both have given their consent to be acknowledged.

\section{References}

1 Townsend MS, Peterson J, Love B, Achterberg C, Murphy SP. Food insecurity is positively related to overweight in women. Journal of Nutrition 2001; 131(6): 1738-45.

2 Basiotis PP, Lino M. Food insufficiency and prevalence of overweight among adult women. Nutrition Insights 2002; 26: $1-2$.

3 Adams EJ, Grummer-Strawn L, Chavez G. Food insecurity is associated with increased risk of obesity in California women. Journal of Nutrition 2003; 133(4): 1070-4.

4 VanEenwyk J, Sabel J. Self-reported concern about food security associated with obesity - Washington, 1995-1999. Morbidity and Mortality Weekly Report 2003; 52(35): 840-2.

5 Olson CM. Nutrition and health outcomes associated with food insecurity and hunger. Journal of Nutrition 1999; 129(2): 521S-4S.

6 Drewnowski A, Specter S. Poverty and obesity: the role of energy density and energy costs. American Journal of Clinical Nutrition 2004; 79(1): 6-16.

7 Frongillo EA. Understanding obesity and program participation in the context of poverty and food insecurity. Journal of Nutrition 2003; 133(7): 2117-8.

8 Jones S, Frongillo EA. The modifying effects of Food Stamp Program participation on the relation between food insecurity and weight change in women. Journal of Nutrition 2006; 136(4): 1091-4.

9 Hill MS. The Panel Study of Income Dynamic: A User's Guide [online], 1991. Available at http://www.sagepub.com/book. aspx?pid=2286. Accessed 21 October 2005.

10 Williamson DF, Kahn HS, Byers T. The 10-y incidence of obesity and major weight gain in black and white US women aged 30-55 y. American Journal of Clinical Nutrition 1991; 53(6): S1515-8.

11 Korkeila M, Rissanen A, Kaprio J, Sørensen TI, Koskenvuo M. Weight-loss attempts and risk of major weight gain: a prospective study in Finnish adults. American Journal of Clinical Nutrition 1999; 70(6): 965-75.
12 Kahn HS, Williamson DF. Is race associated with weight change in US adults after adjustment for income, education, and marital factors? American Journal of Clinical Nutrition 1991; 53(6): S1566-70.

13 Jeffery RW, McGuire MT, French SA. Prevalence and correlates of large weight gains and losses. International Journal of Obesity and Related Metabolic Disorders 2002; 26(7): 969-72.

14 St Jeor ST, Brunner RL, Harrington ME, Scott BJ, Daugherty SA, Cutter GR, et al. A classification system to evaluate weight maintainers, gainers, and losers. Journal of the American Dietetic Association 1997; 97(5): 481-8.

15 Carlson SJ, Andrews MS, Bickel GW. Measuring food insecurity and hunger in the United States: development of a national benchmark measure and prevalence estimates. Journal of Nutrition 1999; 129(2): 510S-6S.

16 Frongillo EA. Validation of measures of food insecurity and hunger. Journal of Nutrition 1999; 129(2): 506S-9S.

17 Winicki J, Jemison K. Food insecurity and hunger in the kindergarten classrooms: its effect on learning and growth. Contemporary Economic Policy 2003; 21(2): 145-57.

18 Jyoti DF, Frongillo EA, Jones SJ. Food insecurity affects school children's academic performance, weight gain, and social skills. Journal of Nutrition 2005; 135(12): 2831-9.

19 Rooney BL, Schauberger CW. Excess pregnancy weight gain and long-term obesity: one decade later. Obstetrics and Gynecology 2002; 100(2): 245-52.

20 Sobal J, Rauschenbach B, Frongillo EA. Marital status changes and body weight changes: a US longitudinal analysis. Social Science \& Medicine 2003; 56(7): 1543-55.

21 Burke G, Bild DE, Hilner JE, Folsom AR, Wagenknecht LE, Sidney S. Differences in weight gain in relation to race, gender, age and education in young adults: the CARDIA study. Ethnicity \& Health 1996; 1(4): 327-35.

22 Harris HE, Ellison GTH. Do the changes in energy balance that occur during pregnancy predispose parous women to obesity? Nutrition Research Review 1997; 10: 57-81.

23 Rowland ML. Self-reported weight and height. American Journal of Clinical Nutrition 1990; 52(6): 1125-33.

24 Devine CM, Wolfe WS, Frongillo EA Jr, Bisogni CA. Lifecourse events and experiences: association with fruit and vegetable consumption in 3 ethnic groups. Journal of the American Dietetic Association 1999; 99(3): 309-14. 